\title{
Self-reporting molecularly imprinted polymer with the covalently immobilized ferrocene redox probe for selective electrochemical sensing of p-synephrine
}

\author{
Patrycja Lach $^{a}$, Maciej Cieplak ${ }^{\mathrm{a}, *}$, Krzysztof R. Noworyta ${ }^{\mathrm{a}}$, Piotr Pieta ${ }^{\mathrm{a}}$, Wojciech Lisowski ${ }^{\mathrm{a}}$, \\ Jakub Kalecki ${ }^{a}$, Raghu Chitta ${ }^{b}$, Francis D'Souza ${ }^{\text {c, } * *}$, Wlodzimierz Kutner ${ }^{a, d} *$, \\ Piyush Sindhu Sharma ${ }^{a}$ \\ ${ }^{a}$ Institute of Physical Chemistry, Polish Academy of Sciences, Kasprzaka 44/52, 01-224 Warsaw, Poland \\ ${ }^{\mathrm{b}}$ Department of Chemistry, National Institute of Technology Warangal, Hanamkonda 506004, Telangana, India \\ ${ }^{\mathrm{c}}$ Department of Chemistry, University of North Texas, 1155 Union Circle, \#305070, Denton, TX 76203-5017, USA \\ ${ }^{\mathrm{d}}$ Faculty of Mathematics and Natural Sciences, School of Sciences, Cardinal Stefan Wyszynski University in Warsaw, Wóycickiego 1/3, 01-815 Warsaw, Poland
}

\section{A R T I C L E I N F O}

\section{Keywords:}

Molecularly imprinted polymer

Electrochemical sensor

Conductive polymer

Electrochemically self-reporting polymer

Ferrocene

Gate effect

\begin{abstract}
A B S T R A C T
Simultaneously, the $p$-synephrine 1 template was imprinted, and a ferrocene redox probe was covalently immobilized in a (bis-bithiophene)-based polymer, and the resulting molecularly imprinted polymer (MIP) was deposited on the Pt electrode as a thin film to form a redox self-reporting MIP film-based chemosensor. After subsequent template extraction from the film, analyte $\mathbf{1}$ was determined with differential pulse voltammetry (DPV) in a (redox probe)-free solution. That was possible because the internal ferrocene redox probe generated the DPV analytical signal. The thickness and morphology of the film were crucial for the sensor's performance. The self-reporting mechanism was examined with electrochemical techniques, simultaneous piezomicrogravimetry and electrochemistry at an electrochemical quartz crystal microbalance, and surface plasmon resonance spectroscopy. The chemosensor was applied for selective $p$-synephrine determination in a concentration range of 2.0-75 $\mathrm{nM}$ with the LOD of $0.57 \mathrm{nM}$ at $S / N=3$.
\end{abstract}

\section{Introduction}

Molecularly imprinted polymers (MIPs, Section S1 in Supplementary material) belong to the illustrious examples of bio-mimicking recognizing materials [1-3]. Their analytical parameters, such as sensitivity, selectivity, and detectability, are almost as high as those of biosensors. Moreover, MIP-based chemosensors are superior to biosensors concerning their ease of fabrication, durability, and tolerance to harsh experimental conditions, including elevated or decreased temperature, high ionic strength, extreme $\mathrm{pH}$ values, the presence of heavy metal ions and organic solvents in the samples. Therefore, MIP thin films may serve as selective recognizing units in chemosensors [4]. Therefore, MIP-based chemosensors found numerous applications in environmental analysis [5], food quality control [6], and clinical analysis [7], to name a few. Conductive MIPs have recently become more frequently applied [8]. That is mainly due to the easy control of MIPs deposition on electrodes, as thin films, by electropolymerization.

For the electrochemical determination of non-electroactive analytes, some external redox probe is usually added to the test solution. It is assumed that target analyte molecules' binding into molecular cavities causes MIP film swelling or shrinking. According to the so-called "gate effect" mechanism, this polymer "breathing" causes changes in the redox probe permeability through an MIP film, thus changing faradaic current corresponding to the redox probe's reduction or oxidation in cyclic voltammetry (CV) and differential pulse voltammetry (DPV) determinations [9-11]. This mechanism is operative for nonconductive MIP films. Another mechanism may be considered for surface imprinted macromolecular compounds, e.g., proteins. A decrease in the faradaic current of the redox probe accompanying protein adsorption originates from physical blocking of the electrode surface by their bulky nonconductive molecules [12-14]. But both these mechanisms seem to be invalid in the case of electrochemical sensors based on conductive MIP

\footnotetext{
* Corresponding authors at: Institute of Physical Chemistry, Polish Academy of Sciences, Kasprzaka 44/52, 01-224 Warsaw, Poland.

** Corresponding author.

E-mail addresses: mcieplak@ichf.edu.pl (M. Cieplak), Francis.DSouza@UNT.edu (F. D’Souza), wkutner@ichf.edu.pl (W. Kutner).
} 

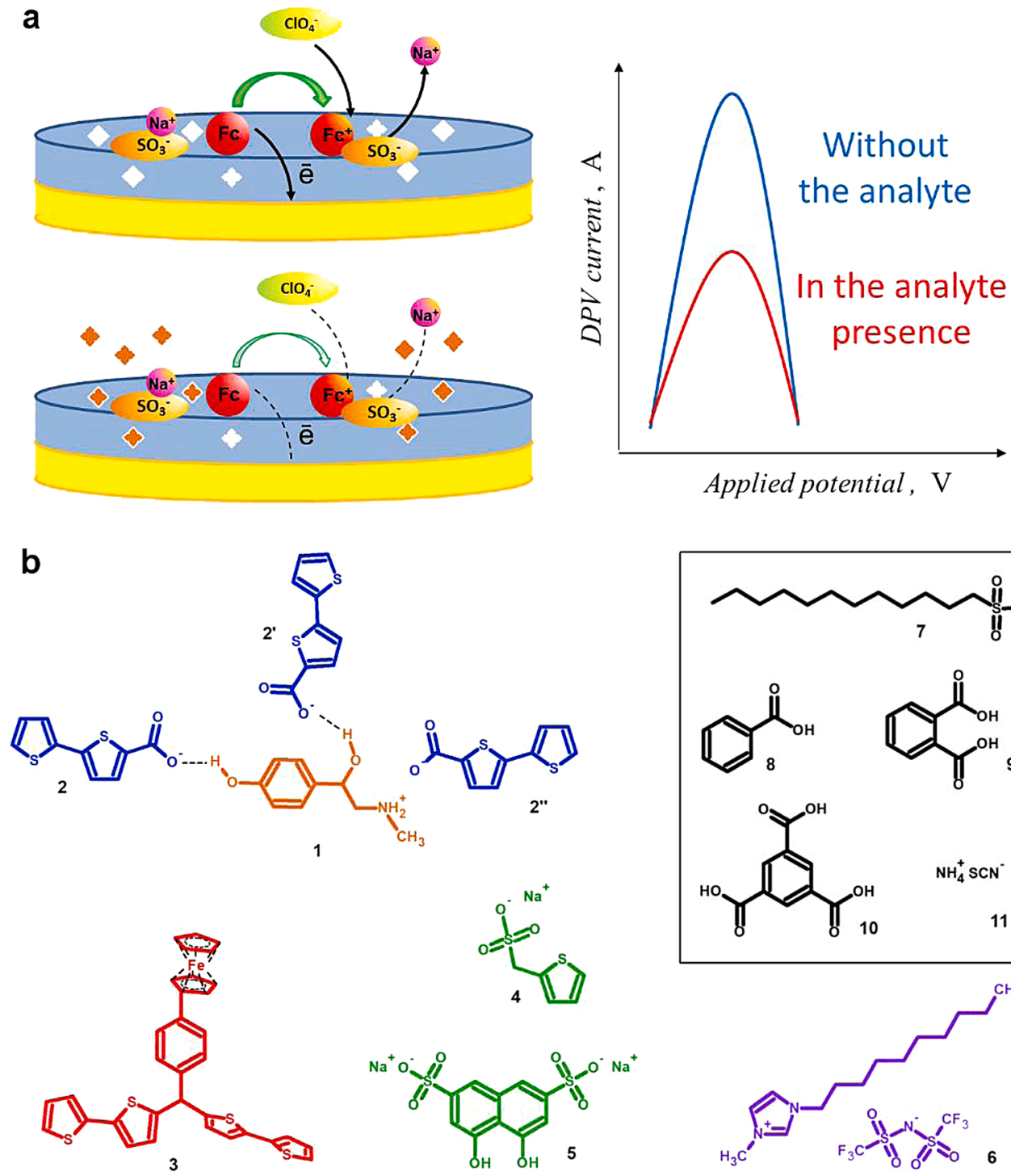

films. We have already demonstrated that a decrease in the DPV current, caused by the appearance in a solution of an analyte, at conductive MIP film-coated electrodes, might originate not from hindering the diffusion of the redox probe through the film but from changes in electrochemical properties of the film itself [15]. Suppose the redox probe diffusion through the MIP film is not a decisive parameter for the faradaic current involving. Then, in the, e.g., DPV determinations of electroinactive analytes at conductive MIP film-coated electrodes, this diffusion may be eliminated. For that, the redox probe could be immobilized inside the MIP film matrix.

Herein, we propose to deposit an electrochemically self-reporting MIP film and apply it for fabricating selective electrochemical chemosensors determining the target analyte in the (redox probe)-free test solutions (Scheme 1a). For comparing a new self-reporting MIP chemosensor with the traditional ("gate effect")-based chemosensor, a system of the well-known template and functional monomers was purposefully chosen [15]. Accordingly, we used $p$-synephrine 1 (Section S2 in Supplementary material) as the model template and then as the target analyte [16]. Notably, 1 - a dietary supplement triggering weight loss, is considered to cause such undesirable severe side effects as elevated blood pressure and heart rate, cardiac arrhythmia, and myocardial infarction [17]. Moreover, we have chosen 2,2'-bithiophene-5-carboxylic acid $\mathbf{2}$ as the functional monomer capable of forming the

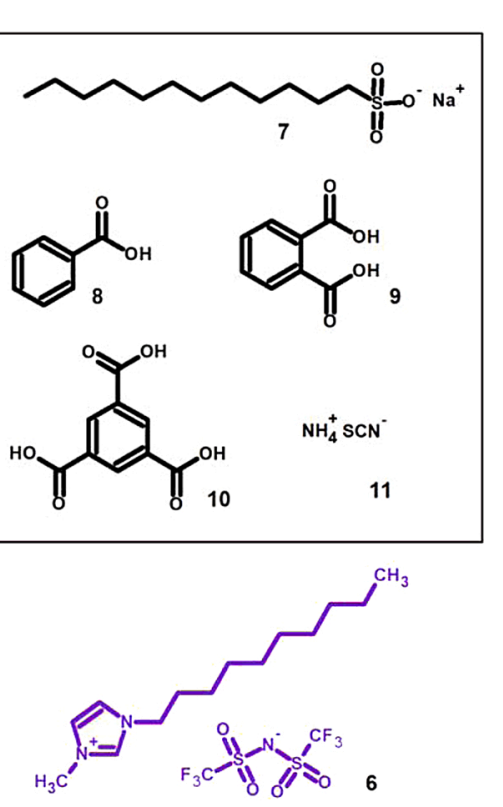

\section{Procedures}

Scheme 1. (a) Illustration of a DPV signal generation at a self-reporting MIP film-coated electrode in the absence or the presence of the $p$-synephrine 1 analyte in the test solution and corresponding analytical DPV signals. (b) The structural formula proposed for the pre-polymerization complex of the 1 template molecule with three molecules of $2,2^{\prime}$-bithiophene-5-carboxylic acid 2 as well as the structural formulas of bis- $\left(2,2^{\prime}\right.$ bithienyl)-4-ferrocenylphenyl methane 3, sodium thiophen-2-ylmethanesul fonate 4, chromotropic acid disodium salt 5, 1-decyl-3-methylimidazolium bis(trifluoromethanesulfonyl)imide 6 ionic liquid, and lipophilic anions providing compounds 7-11.

pre-polymerization complex with $\mathbf{1}$, enabling selective recognition of 1 by the deposited MIP-1 film (Scheme 1b). Bis-(2,2'-bithienyl)-4-ferrocenylphenyl methane $\mathbf{3}$ was specially designed and then synthesized. This monomer played a dual role. On the one hand, it provided an internal redox probe, namely, the ferrocene moiety, and it served as the cross-linking monomer on the other. It formed the main polymer matrix constituting a rigid framework for immobilization of functional monomers on the imprinted molecular cavities' walls (Scheme 1).

Chemicals, instrumentation, the bis-(2,2'-bithienyl)-4-ferrocenylphenylmethane monomer synthesis, and all other experimental procedures are described in Supplementary material.

\subsection{MIP films synthesizing and depositing}

The MIP-I film was prepared by oxidative electropolymerization under potentiodynamic conditions with five potential cycles over the potential range of $0-1.30 \mathrm{~V}$ vs. Ag quasi-reference electrode at a potential scan rate of $50 \mathrm{mV} \mathrm{s}^{-1}$. An acetonitrile solution of $10 \mu \mathrm{M} 1,30 \mu \mathrm{M}$

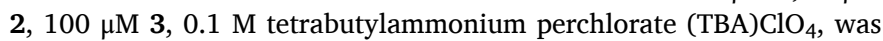
used for this electropolymerization. 

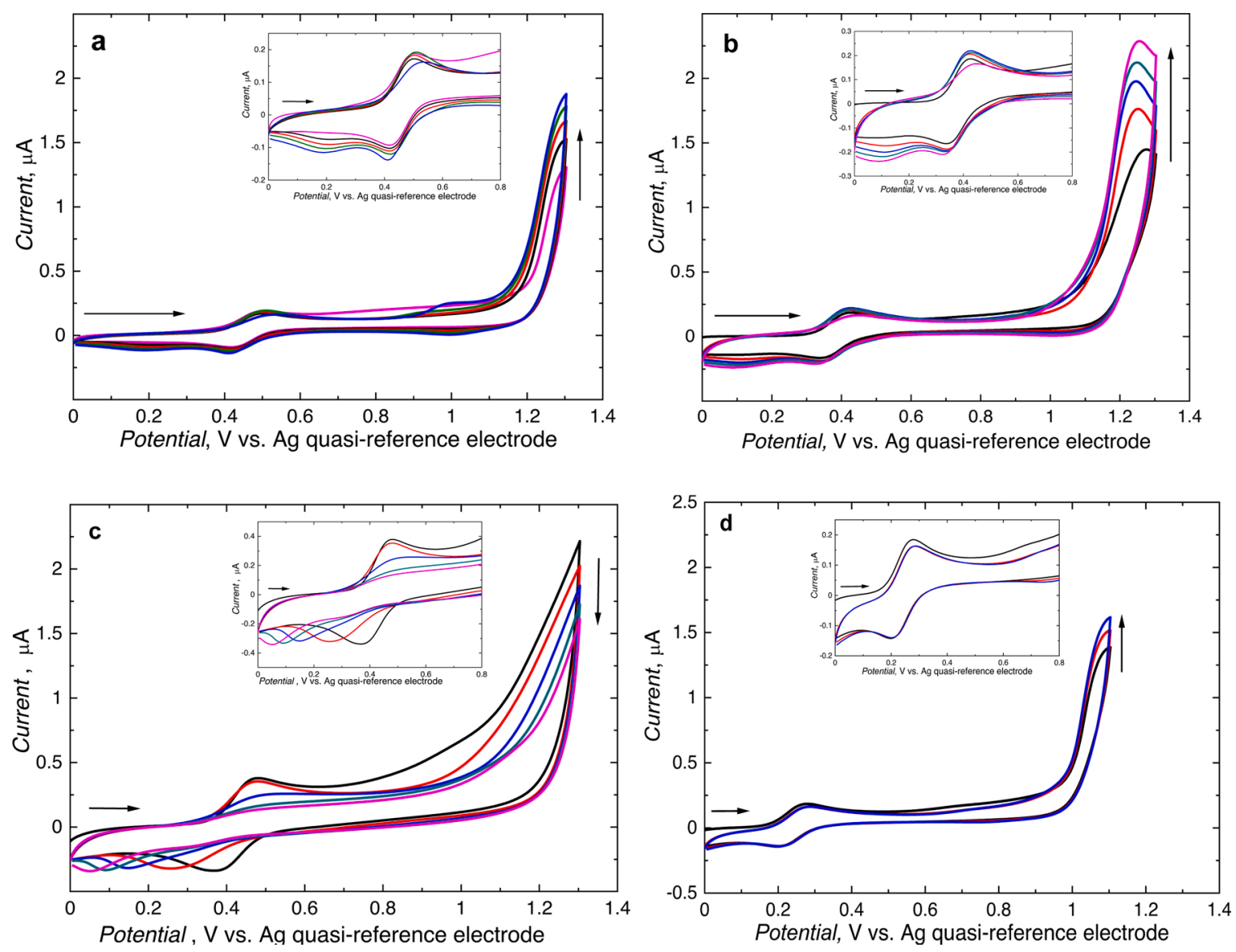

Fig. 1. Potentiodynamic curves recorded during deposition of MIP-I to MIP-IV films on 1-mm diameter Pt disk electrodes from solutions of $10 \mu \mathrm{M} p$-synephrine 1 , 30 $\mu \mathrm{M}$ 2,2'-bithiophene-5-carboxylic acid 2, $100 \mu \mathrm{M}$ bis-(2,2'-bithienyl)-4-ferrocenylphenyl methane 3 (a) solely or in the presence of (b and d) $100 \mu \mathrm{M}$ sodium thiophen-2-ylmethanesulfonate 4, (c) $100 \mu \mathrm{M}$ chromotropic acid disodium salt $\mathbf{5}$ in a mixed solvent solution of (a-c) dichloromethane and acetonitrile, $1: 9, v: v$, or (d) toluene, ionic liquid 6, and acetonitrile at the $1: 2.5: 6.5, v: v: v$ ratio. In all cases, $0.1 \mathrm{M}\left(\mathrm{TBA} \mathrm{ClO}_{4}\right.$ served as the supporting electrolyte.

The MIP-II film was prepared similarly as the MIP-I film except for $100 \mu \mathrm{M}$ sodium thiophen-2-yl methanesulfonate 4 presence in the solution for electropolymerization.

The MIP-III film was prepared similarly as the MIP-I film except for $100 \mu \mathrm{M}$ chromotropic acid disodium salt $\mathbf{5}$ presence in the solution for electropolymerization.

The MIP-IV film was prepared by oxidative electropolymerization under potentiodynamic conditions with three potential cycles over the potential range of $0-1.10 \mathrm{~V}$ vs. Ag quasi-reference electrode at a potential scan rate of $50 \mathrm{mV} \mathrm{s}^{-1}$. A solution of $10 \mu \mathrm{M} \mathrm{1}, 30 \mu \mathrm{M} 2,100 \mu \mathrm{M}$ $3,100 \mu \mathrm{M}$ sodium thiophen-2-ylmethanesulfonate 4 , and $0.1 \mathrm{M}$ (TBA) $\mathrm{ClO}_{4}$ in toluene, the 1-decyl-3-methylimidazolium bis(trifluoromethanesulfonyl)imide 6 ionic liquid, and acetonitrile at the 1 : $2.5: 6.5, \underline{v}: \underline{v}: \underline{v}$ ratio was used for this electropolymerization.

\section{Results and discussion}

There are only a few examples of ferrocene containing monomers application for MIP films deposition. These monomers, namely, vinyl ferrocene [18-20] and ferrocenylmethyl methacrylate [19,21], were incorporated into polyacrylic MIP nanoparticles embedded inside carbon paste electrodes [18] or drop-cast on the glassy carbon $[19,20]$ and carbon screen-printed electrodes [21]. In these studies, ferrocene was integrated to facilitate electron transfer for electrochemical determination of electroactive analytes $[20,21]$ or as a functional monomer interacting with the analyte via $\pi-\pi$ stacking [18]. Moreover, some attempts were made to apply copolymerized vinyl ferrocene monomers as internal redox probes $[18,19]$. However, the faradaic currents generated were very small. Therefore, both reported sensors' sensitivity and detectability were unsatisfactory. A possible reason might be that an insufficient number of ferrocene moieties was electro-oxidized. Only ferrocene redox centers located close to the electrode surface were electroactive because the electrical double-layer is usually well thinner than $1 \mathrm{~nm}$ [22].

Herein, we adopted a different approach. That is, the (bis-bithiophene)-based monomer was appended with ferrocene and then copolymerized with a bithiophene-based functional monomer in the presence of the $p$-synephrine template to produce a conductive MIP film. This film facilitated the electron exchange between the electrode substrate and the ferrocene moieties, mediated by the poly(bis-bithiophene) backbone. This mediation resulted in much higher faradaic currents of the internal ferrocene redox probe and, therefore, enhanced MIP chemosensor sensitivity and detectability.

\subsection{Synthesizing and depositing MIP films}

The MIP-I film selective to $\mathbf{1}$ was synthesized and deposited on the Pt disk electrode surface in the way described in Section 2, above (Fig. 1a). The anodic peak of bis-bithiophene oxidation at $1.20 \mathrm{~V}$ vs. Ag quasireference electrode and the current increase in consecutive cycles indicate that the deposited polymer film is conductive. Moreover, a pair of symmetric ferrocene anodic and cathodic peaks are present in the potential range of 0.40 to $0.50 \mathrm{~V}$ vs. Ag quasi-reference electrode. With the electropolymerization progress, the peak-to-peak separation increased from 88 to $122 \mathrm{mV}$, suggesting that either this one-electron process changed from electrochemically quasi-reversible to electrochemically 

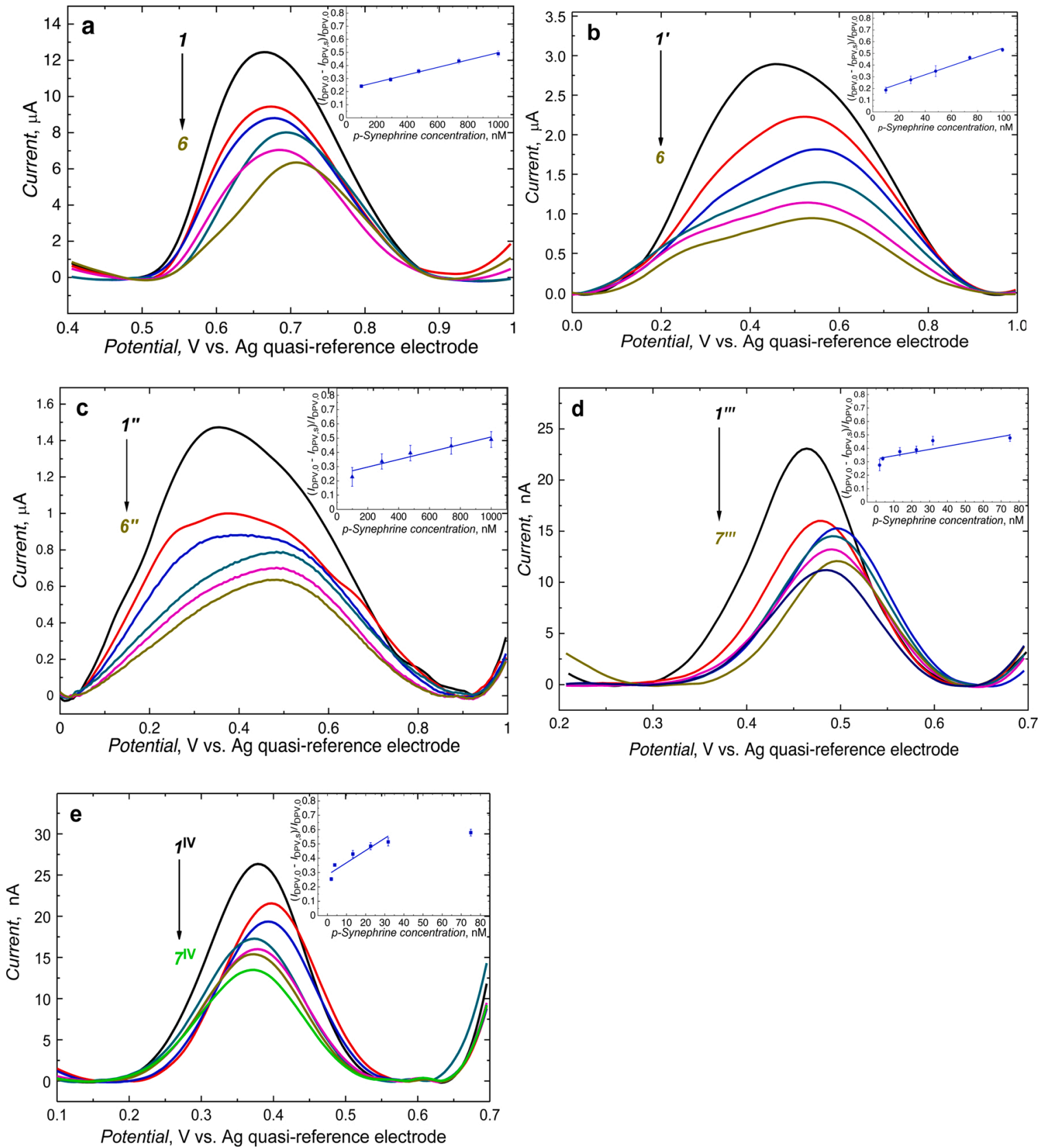

Fig. 2. The DPV curves for the Pt disk electrode coated with a film of (a and d) MIP-I, (b and e) MIP-II, and (c) MIP-III (1) after template 1 extraction with 0.1 M $\mathrm{NaOH}$, and then the addition of $p$-synephrine to result in its concentration of $\left(2\right.$ and $\left.2^{\prime \prime}\right) 100$, (3 and $\left.3^{\prime \prime}\right) 290$ (4 and $\left.4^{\prime \prime}\right) 480,\left(5\right.$ and $\left.5^{\prime \prime}\right) 740$, and (6 and $\left.6^{\prime \prime}\right) 990 \mathrm{nM}$, or $\left(2^{\prime}\right) 10,\left(3^{\prime}\right) 29\left(4^{\prime}\right) 48,\left(5^{\prime}\right) 74$, and $\left(6^{\prime}\right) 99 \mathrm{nM}$, or $\left(2^{\prime \prime \prime}\right.$ and $\left.2^{\mathrm{IV}}\right) 2.0\left(3^{\prime \prime \prime}\right.$ and $\left.3^{\mathrm{IV}}\right) 3.8\left(4^{\prime \prime \prime}\right.$ and $\left.4^{\mathrm{IV}}\right) 13.3\left(5^{\prime \prime \prime}\right.$ and $\left.5^{\mathrm{IV}}\right) 22.6\left(6^{\prime \prime \prime}\right.$ and $\left.6^{\mathrm{IV}}\right) 31.7\left(7^{\prime \prime \prime}\right.$ and $\left.7^{\mathrm{IV}}\right) 75 \mathrm{nM}$. Measurements were performed using (b and c) $0.1 \mathrm{M} \mathrm{PBS}\left(\mathrm{pH}=7.4\right.$ ), (a) $0.1 \mathrm{M} \mathrm{PBS} \mathrm{(pH} \mathrm{=} \mathrm{7.4)} \mathrm{and} 0.1 \mathrm{M} \mathrm{NH}_{4} \mathrm{SCN}$, and (d and e) $0.1 \mathrm{M}(\mathrm{TBA}) \mathrm{ClO}{ }_{4}$ in acetonitrile. Respective insets show calibration plots constructed for the data acquired.

irreversible or, otherwise, because of a pronounced MIP film resistivity the ohmic potential loss increased with the current increase. It is conceivable that the counter ion diffusion in and out of the film for charge compensation could not keep up with the ferrocene moiety charging and discharging.

Moreover, the height of this peak did not change in consecutive cycles. Apparently, this redox process in an acetonitrile solution proceeds only in the electrical double layer located at the Pt-(MIP film) or (MIP film)-(acetonitrile solution) interface. Therefore, deposition of subsequent MIP layers accompanying consecutive cycles only slightly influenced this process.
3.2. Optimizing the MIP film composition for p-synephrine determination in $P B S$

Although the ferrocene CV anodic and cathodic peaks were well pronounced during MIP-I film deposition, after template extracting and subsequent MIP-I film-coated electrode transferring to a blank PBS (pH $=7.4$ ) solution, a DPV peak was not seen in the range of 0 to $0.90 \mathrm{~V}$ vs. Ag quasi-reference (Fig. S4 in Supplementary material). We speculate that it was because hydrophilic phosphate and chloride anions were unable to enter the hydrophobic poly(bis-bithiophene) film to compensate for a positive charge generated on the ferrocene moieties during 
their electro-oxidation. Therefore, different lipophilic salts 7-11, added to the test solution, were examined to enable the ferrocene moiety's electro-oxidation. Only for $0.1 \mathrm{M} \mathrm{NH}_{4} \mathrm{SCN} \mathrm{11}$, a broad DPV ferrocene peak at $0.65 \mathrm{~V}$ vs. Ag quasi-reference was observed (Fig. 2a). Most importantly, this peak decreased with the increase of the 1 concentration in solution in the range of 0.1 to $0.99 \mu \mathrm{M}$, thus obeying the linear regression equation of $\left(I_{\mathrm{DPV}, 0}-I_{\mathrm{DPV}, \mathrm{s}}\right) / I_{\mathrm{DPV}, 0}=0.22( \pm 0.01)+2.82 \times$ $10^{-4}\left( \pm 0.12 \times 10^{-4}\right) c_{p \text {-synephrine, }} \mathrm{nM}$ with the correlation coefficient of $R^{2}=0.9929$. In this equation, the $I_{\mathrm{DPV}, 0}$ and $I_{\mathrm{DPV}, \mathrm{s}}$ symbols stand for the DPV initial and actual peak current, respectively. The 1 limit of detection (LOD) was $28.93 \mathrm{nM}$ at a signal-to-noise $(S / N)$ ratio of 3 .

Introducing additional salts into test solutions to promote ferrocene oxidation is a rather inconvenient way of determining the $\mathbf{1}$ analyte in a (redox probe)-free solution. Therefore, a new MIP film, namely, MIP-II, was prepared with sodium thiophen-2-ylmethanesulfonate 4 copolymerized with monomer 3 at the $1: 1 \mathrm{M}$ ratio (Fig. 1b). In this case, the bis-bithiophene anodic peak at $1.20 \mathrm{~V}$ vs. Ag quasi-reference electrode grew in consecutive potential cycles. Moreover, the ferrocene anodic and cathodic peak pair was visible in the range of 0.35 to $0.40 \mathrm{~V}$ vs. $\mathrm{Ag}$ quasi-reference electrode. In the MIP-II film thus deposited, both the ferrocene moiety and the anion were covalently embedded. Therefore, after template extracting and the MIP-II film-coated electrode transferring to the blank PBS ( $\mathrm{pH}=7.4)$ solution, the ferrocene moiety's DPV peak was well developed (Fig. 2b). Presumably, ferrocene moiety electro-oxidation resulted in expelling cations from the MIP film, namely, sodium and potassium, for maintaining film electroneutrality. Moreover, the potential of this peak was less positive than that for the MIP-I film-coated electrode.

Then, we deposited another MIP film, vis., MIP-III, with entrapped chromotropic acid 5 as the counter ion supplier (Fig. 1c). During the electropolymerization, currents decreased at each consecutive potential cycle, suggesting that the deposited film was not conductive. Furthermore, the separation of the anodic and cathodic peak potentials corresponding to ferrocene electro-oxidation and electroreduction, respectively, increased, and the peak current decreased with each electropolymerization cycle. Ultimately, it disappeared in the last cycle. Presumably, MIP-III film permeability for perchlorate ions was low. Consequently, these ions could not enter or leave the film to sustain the film's electroneutrality after the thicker film's deposition.

After template 1 extraction, electrodes coated with the above MIP films were applied for DPV determinations of 1 in the PBS ( $\mathrm{pH}=7.4$ ) solution. For the MIP-II and MIP-III film-coated electrodes, currents were four- and eight-times lower than those for the MIP-I film-coated electrode in the $\mathrm{NH}_{4} \mathrm{SCN}$ presence, respectively (Fig. $2 \mathrm{~b}$ and 2c). However, there was no need for the addition of $\mathrm{NH}_{4} \mathrm{SCN}$ to the test solutions for the peak to appear. Moreover, relative changes of DPV peak currents with 1 concentration changes for the MIP-II film-coated electrode (Fig. 2b, inset and Table S5 in Supplementary material) were $\sim 14$ times higher than those for the MIP-I and MIP-III film-coated electrodes (Fig. 2a and 2c, insets, Table S5 in Supplementary material).

Significantly, the MIP-II film-coated electrode sensitivity to the $\mathbf{1}$ analyte was ten times higher than that of previously reported MIP filmcoated electrodes where the MIP film without an internal redox probe but with the hexacyanoferrate redox probe present in the test solution was used for 1 sensing [15]. Unfortunately, the DPV peaks for immobilized ferrocene redox probe were very broad and flattened at both MIP-II and MIP-III film-coated electrodes (Fig. 2b and 2c) if recorded using aqueous test solutions. Moreover, these broadened peaks seem to be composed of two overlapping peaks. We can only dare to speculate that two types of ferrocene moieties of different properties are present in the deposited MIP films. One type is in close vicinity to the polymer-solution interface. Therefore, it is more prone of electro-oxidizing because counter ions from the solution more easily access it. The other type seems to be buried deep in the polymer matrix and is more difficult to oxidize.

\subsection{Optimizing composition of MIP films for p-synephrine determination in non-aqueous solvent solutions}

A (TBA) $\mathrm{ClO}_{4}$ hydrophobic supporting electrolyte in acetonitrile was applied for 1 determination with DPV to facilitate more efficient diffusion of ions through the MIP-solution interface. The recorded DPV peaks in acetonitrile were much narrower (Fig. $2 \mathrm{~d}$ and 2e) than those in the PBS ( $\mathrm{pH}=7.4$ ) solution (Fig. 2a-c). Thus, DPV peak maxima were more pronounced. Therefore, we pursued our studies using non-aqueous solvent solutions. MIP film deposition conditions were carefully optimized to obtain the highest DPV peak after template extraction (Fig. 1d as well as Figs. S5, and S6 in Supplementary materials). Two contrary effects were balanced.

The thicker the MIP film deposited, the more ferrocene moieties and more imprinted cavities were present in the film. Therefore, both the currents and film capacity should increase with the film thickness increase. On the other hand, the thicker the film, the higher the distance of the immobilized ferrocene moieties from the MIP-solution and MIPelectrode interfaces. Hence, ion transport and electron transfer are hindered. This effect may result in the observed current decrease for thicker MIP films. Therefore, porous films occurred to be superior (Fig. 5) in comparison to those continuous (Fig. 2d). For that purpose, a porogen, namely, the 1-decyl-3-methylimidazolium bis(trifluoromethanesulfonyl)imide 6 ionic liquid, was added to the solution for electropolymerization. The MIP-IV film thickness was optimal if three potential cycles were performed for electropolymerization in the potential range of 0 and $1.10 \mathrm{~V}$ vs. Ag quasi-reference electrode (Fig. 1d). Currents recorded during the MIP-IV film deposition were slightly lower than those for deposition of the MIP-II film. The above effect resulted from partial electrode surface blocking by ionic liquid 6 mesophase present in the solution for electropolymerization. The MIPIV film thickness was $27( \pm 7) \mathrm{nm}$ (Fig. S9 and Table S3 in Supplementary material).

Moreover, the presence of sulfonyl groups inside the MIP film was necessary for the $\mathbf{1}$ analyte determination in non-aqueous solvent solutions. The MIP-V film was deposited under the same conditions as the MIP-IV film but in the absence of monomer 4 (Fig. S6a in Supplementary material). DPV currents recorded at the MIP-V film-coated electrode before and after template $\mathbf{1}$ extraction were significantly lower than those at the MIP-IV film-coated electrode (Fig. S6b in Supplementary material). Moreover, if the optimized MIP-IV film-coated electrode was used for determining 1 in the PBS $(\mathrm{pH}=7.4)$ solution, the DPV peaks were still broad and flattened (Fig. S7 in Supplementary material). Therefore, all further studies were performed using acetonitrile solutions.

\subsection{Characterizing the MIP-IV and NIP-IV films}

The optimized MIP-IV and NIP-IV films were characterized by PMIRRAS, XPS, and EDX spectroscopy. For all of them, the spectra confirmed the successful deposition of polythiophene films (Fig. S8 and Table S1 in Supplementary material). However, the XPS-determined iron atom concentrations on all films' surfaces were very low, ranging from 0.20 to $1.68 \mathrm{Fe}$ atomic \% (Table S1 in Supplementary material). Therefore, the MIP-IV and NIP-IV films were also examined with EDX spectroscopy (Table S2 in Supplementary material). In this case, the Fe L line was more pronounced, and the calculated iron atomic concentrations in the films were significantly higher; namely, they were equal to 2.7-5.7 Fe atomic \%. Presumably, positively charged ferrocenium moieties were buried deep inside polymer grains during the electropolymerization rather than exposed to the interface with the hydrophobic solvent solution. Therefore, their polymer surface population might be significantly lower than that in the polymer bulk.

Moreover, the fluoride's low content in the films suggests that only a tiny fraction of ionic liquid was entrapped inside the MIP-IV and NIP-IV films. Mostly, it was washed out just after electropolymerization, thus 

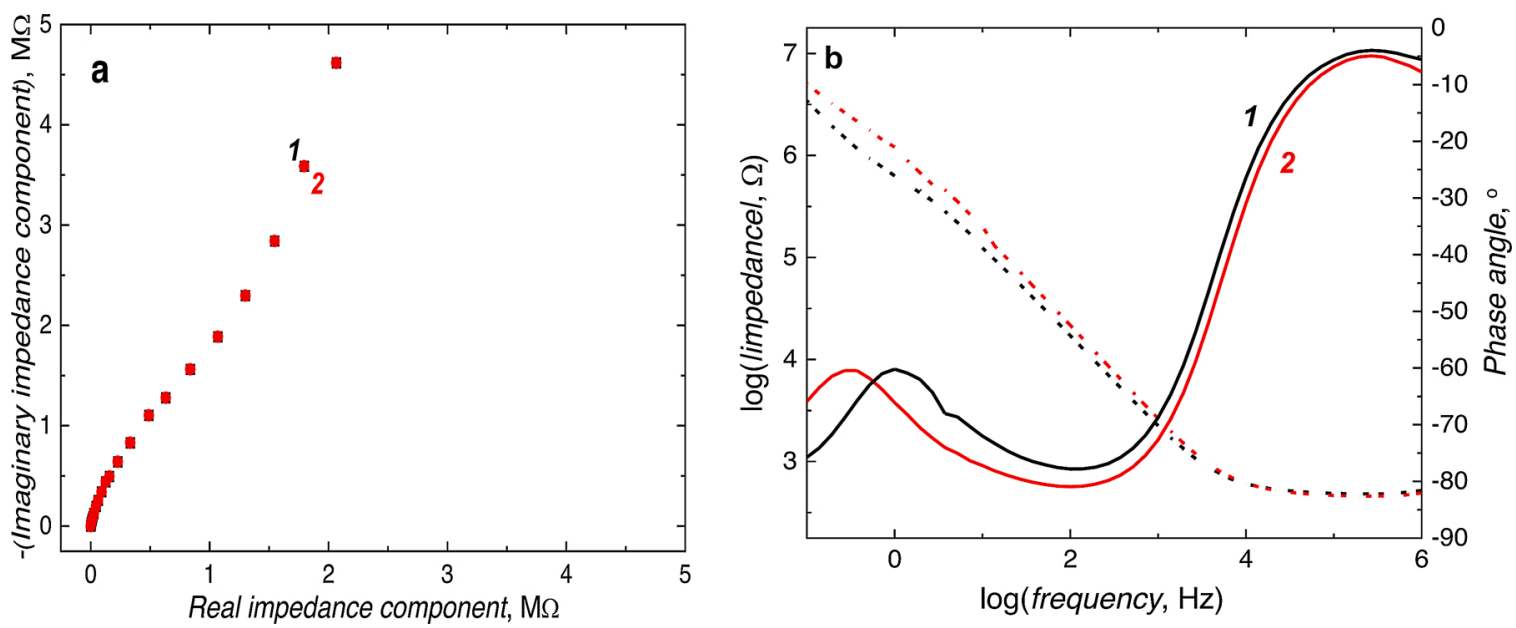

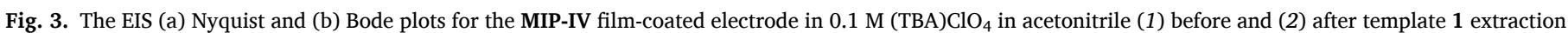
with $0.1 \mathrm{M} \mathrm{NaOH}$.

generating nanopores in the deposited films. This result agrees well with AFM imaging (Fig. S9 and Table S3 in Supplementary material). This imaging of the MIP-IV and NIP-IV films revealed that these films consisted of round and flattened grains of a "pancake-like" shape. These grains' diameter was $90-100 \mathrm{~nm}$, i.e., substantially larger than those of grains of the gold support, vis., $42 \mathrm{~nm}$. Importantly, in both the MIP-IV and NIP-IV films after electropolymerization, many randomly distributed 150-to-200 $\mathrm{nm}$ in diameter pores were present. After 1 extraction, some of these pores contracted. However, most of them remained. The average thickness of the deposited MIP-IV and NIP-IV film after 1 extraction was $27( \pm 7)$ and $21( \pm 5) \mathrm{nm}$, and their roughness measured on their top surface was $5.0( \pm 1.4)$ and $4.5( \pm 1.9) \mathrm{nm}$, respectively. Details of the nanomechanical film properties are described in Supplementary material.
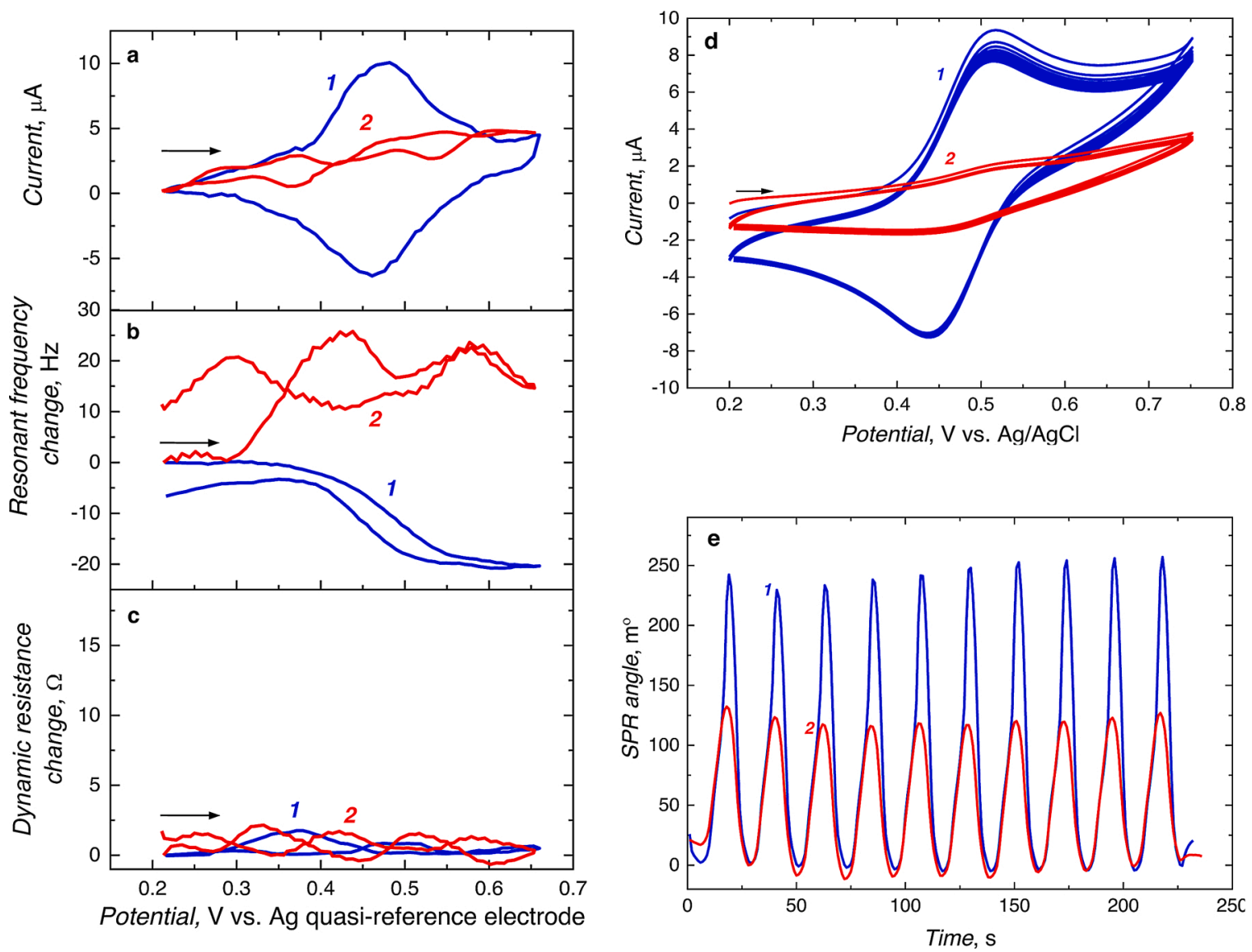

Fig. 4. Curves of the potential dependence of the (a) current, (b) resonant frequency change, and (c) dynamic resistance change for the MIP-IV film-coated Au-QCR. (d) The multi-cyclic CV curve, and (e) the simultaneously recorded SPR angle change with time for the MIP-IV film-coated SPR chip. Measurements were performed using $0.1 \mathrm{M}(\mathrm{TBA}) \mathrm{ClO}_{4}$ in acetonitrile (1) after p-synephrine template extraction with $0.01 \mathrm{M} \mathrm{Et}_{3} \mathrm{~N}$ in acetonitrile and (2) after the solution was made $40 \mathrm{nM}$ in 1. 

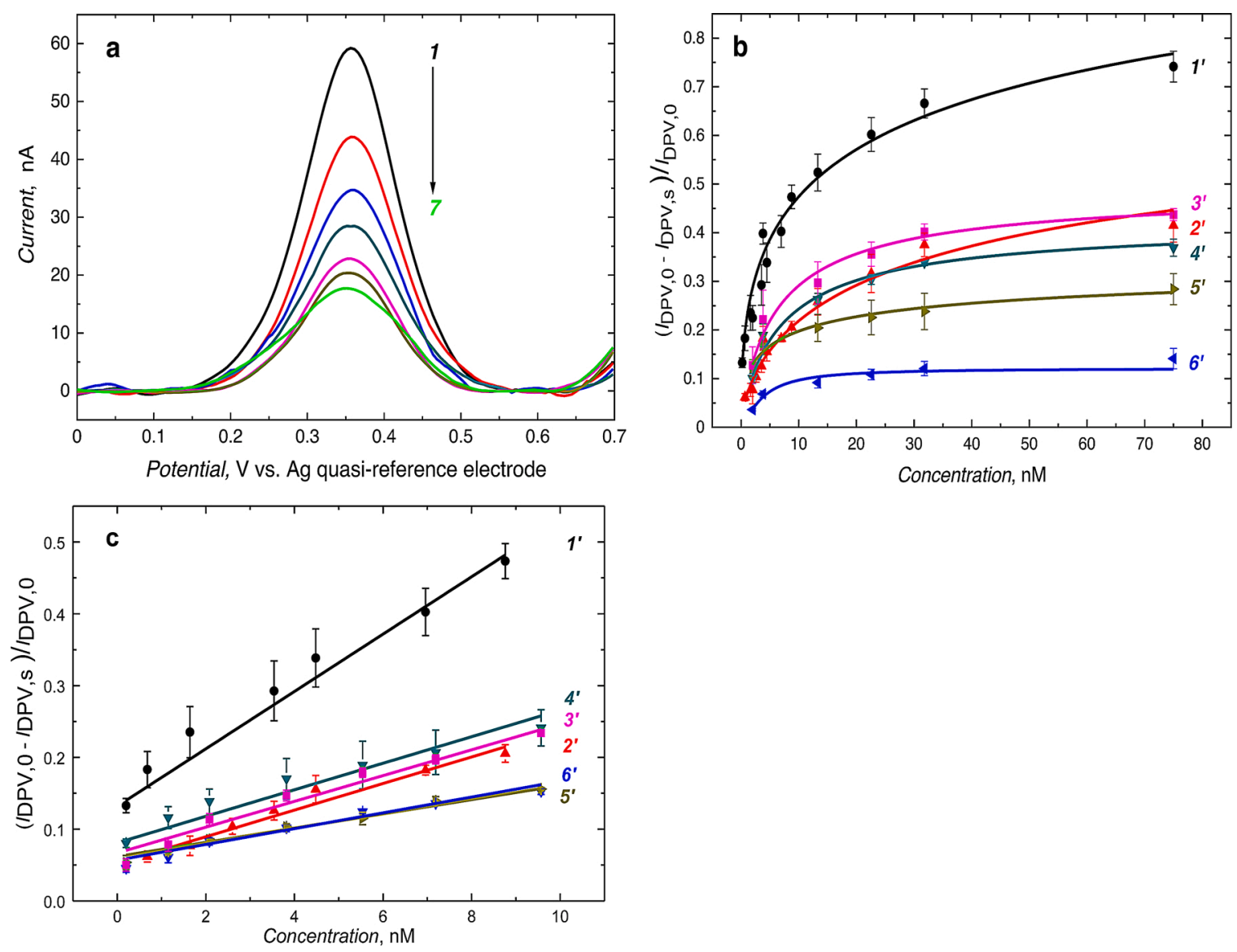

Fig. 5. (a) Changes in the DPV peak current for the MIP-IV film-coated Pt disk electrode (1) after $p$-synephrine template extraction with $10 \mathrm{mM} \mathrm{Et}_{3} \mathrm{~N}$ in acetonitrile for $5 \mathrm{~min}$ as well as after addition of $p$-synephrine to reach the concentration of (2) 2.0 (3) 3.8 (4) 13.3 (5) 22.6 (6) 31.7 (7) $75 \mathrm{nM}$. (b) Langmuir-Freundlich isotherm fitting and (c) calibration plots for $\left(1^{\prime}\right.$ and $\left.2^{\prime}\right)$ p-synephrine, $\left(3^{\prime}\right)$ penicillin G, $\left(4^{\prime}\right)$ glucose, $\left(5^{\prime}\right)$ tyramine, and $\left(6^{\prime}\right)$ urea at $\left(1^{\prime}, 3^{\prime}-6^{\prime}\right)$ at the MIP-IV film- and $\left(2^{\prime}\right)$ the NIP film-coated Pt disk electrode. Measurements were performed using $0.1 \mathrm{M}(\mathrm{TBA}) \mathrm{ClO}_{4}$ in acetonitrile.

\subsection{Unraveling mechanism of the self-reporting electrochemical MIP-IV chemosensor response}

The mechanism of the (MIP-IV)-based chemosensor electrochemical response was unraveled.

For that purpose, the EIS spectra in the range of $10 \mathrm{MHz}$ to $100 \mathrm{mHz}$ were recorded at the potential of $E=0.20 \mathrm{~V}$ vs. Ag quasi-reference to gain more in-depth insight into mechnism of the electrochemical process. In the Nyquist plots, the expected semicircle corresponding to the charge transfer resistance was not developed [15]. Instead, the shape of these plots (Fig. 3) was characteristic for diffusion in thin films with mixed reflecting-absorbing boundary at predomination of the reflecting boundary [23]. This effect can be interpreted as ion diffusion through the semiconductive porous film [24,25] and/or electron transport through the intrinsically conducting polymer film [26]. Curves, recorded before and after 1 extraction, were quite similar. However, there were significant differences in the Bode plot's phase angle vs. logarithm frequency in the low-frequency range, i.e., below $10 \mathrm{~Hz}$ (Fig. 3b). For the MIP-IV film-coated electrode before extraction, a minor "kink-like" feature below $\sim 1 \mathrm{~Hz}$ is observed in the logarithm of impedance modulus vs. logarithm of frequency curve.

In contrast, the phase angle vs. logarithm of frequency curve exhibits a peak at $1 \mathrm{~Hz}$ (black dotted curve and curve 1 in Fig. 3b, respectively). These results indicate the presence of pores in the polymer film [27]. However, the peak shifts toward lower frequencies after 1 extraction suggesting a pore density decrease (curve 2 in Fig. 3b). These results agree with the AFM images. Moreover, the phase angle peak decreased and further shifted towards lower frequencies with the $\mathbf{1}$ concentration increase (Fig. S10 in Supplementary material). These results confirm that MIP-IV molecular cavities bind $\mathbf{1}$ molecules lowering the polymer film's porosity.

Afterward, the MIP-IV film electrochemical sensor performance was examined with both the piezoelectric microgravimetry at the electrochemical quartz crystal microbalance (EQCM) and electrochemical surface plasmon spectroscopy (E-SPR). At the MIP-IV film-coated Au$\mathrm{QCR}$, the current of ferrocene moiety electro-oxidation and electroreduction (Fig. 4a) was recorded simultaneously with the resonance frequency change (Fig. 4b) and dynamic resistance change (Fig. 4c) during potential cycling from 200 to $650 \mathrm{mV}$ vs. Ag quasi-reference electrode. However, when the MIP-IV film was deposited under conditions optimized for electrochemical determinations and CV was executed in the same way that led to the results shown in Fig. 4a, the signal-to-noise ratio was too low. Moreover, frequency changes were irreproducible. Therefore, MIP-IV film deposition on the Au-QCR (Fig. S11 in Supplementary material) was optimized for that purpose.

Moreover, tetraethylammonium perchlorate (TEA) $\mathrm{ClO}_{4}$ was used instead of (TBA) $\mathrm{ClO}_{4}$ as the supporting electrolyte salt. Cations of the former electrolyte are smaller and more mobile. Under these conditions, evident changes in the resonant frequency were seen due to ferrocene moiety electro-oxidation and electroreduction in the $\mathrm{CV}$ experiment. During the electro-oxidation, the charge of $42.77 \mu \mathrm{C}$ was transferred. That is, $0.44 \mathrm{nmol}$ of positively charged ferrocene moiety was generated. As expected, the anodic and cathodic peak separation for ferrocene electro-oxidation and electroreduction was small, thus indicating the occurrence of a thin-layer electrochemical process (Fig. 4a). During the electropolymerization (Fig. S11 in Supplementary material), 37.82 $\mu \mathrm{g}$ of 
MIP-IV film was deposited on the Au-QCR surface. The integration of the CV curve between 0.20 and $0.60 \mathrm{~V}$ vs. Ag quasi-reference electrode charge during polymer deposition allowed estimating the amount of the ferrocene moiety in the MIP film deposited to be $1.11 \mathrm{nmol}$. Therefore, $\sim 40 \%$ of ferrocene moieties were electro-oxidized, being responsible for the chemosensor response.

Surprisingly, resonance frequency dropped by $20.6( \pm 0.8) \mathrm{Hz}$ after ferrocene moiety electro-oxidation. During the potential cycling, the dynamic resistance change (Fig. $4 \mathrm{c}$ ) was very small, indicating that the film rigidity was not affected. That is, the effect of MIP-IV film swelling and shrinking was minor. Therefore, the resonance frequency change could be recalculated to the polymer mass change using the Sauerbrey relation (Eq. 1) [28].

$\Delta f=-\frac{2 f_{0}^{2}}{A \sqrt{p_{\mathrm{q}} \mu_{\mathrm{q}}}} \Delta m$

In this equation, $\Delta f, f_{0}, A, p_{\mathrm{q}}, \mu_{\mathrm{q}}$, and $\Delta m$ stands for the change of the resonant frequency of the fundamental mode $(\mathrm{Hz})$, the normalized frequency change $(\mathrm{Hz})$, the crystal piezoelectrically active area $\left(\mathrm{cm}^{2}\right)$, quartz density $\left(2.648 \mathrm{~g} \mathrm{~cm}^{-3}\right)$, quartz shear modulus $\left(2.947 \mathrm{~g} \mathrm{~cm}^{-1} \mathrm{~s}^{-2}\right)$, and the mass change $(\mathrm{g})$, respectively. With the Sauerbrey equation, we determined the polymer mass increase by $1.79 \mathrm{ng}$ during ferrocene moiety electro-oxidation (Fig. 4a), which contrasts with the expected mechanism. This mass increase can be attributed to the ingress of only 18 pmol of the perchlorate ion into the MIP-IV film. This number of moles is much lower than that of the electro-oxidized ferrocene moiety. Therefore, we may assume that the perchlorate counter-ion ingress to the film and the cation co-ion egress coincided. However, the perchlorate ion ingress slightly prevailed. Moreover, during the backward scan, the resonant frequency increased. It equilibrated at the level by $6.5 \mathrm{~Hz}$ lower than that original, suggesting that 5.68 pmol of the perchlorate ion from the solution was entrapped in the film.

After injection of a sample of $40 \mathrm{nM}$ of $\mathbf{1}$, the CV curve was significantly flattened, and almost no faradaic currents were flowing (Fig. 4a). However, resonant frequency significantly increased at the potential of ferrocene moieties oxidation (Fig. 4b). Presumably, a small fraction of the ferrocene moieties was still electroactive. However, only cations were expelled from the MIP-IV film in this case, thus causing a drop in the polymer film mass. It may suggest that mainly perchlorate ion diffusion from the solution to the film was affected by 1 binding into MIP-IV film imprinted cavities.

Furthermore, SPR chips were coated with MIP-IV films (Fig. S12 in Supplementary material). It was necessary to deposit the MIP-IV film under the same conditions as those optimized for EQCM experiments to obtain well-developed CV ferrocene peaks. Simultaneously with the CV measurements (Fig. 4d), the SPR signal changes were recorded (Fig. 4e). During each consecutive CV cycle, the SPR angle largely increased due to ferrocene moiety electro-oxidation. Moreover, the SPR signal returned to its baseline after ferrocene moiety electroreduction. The height of the SPR peaks was in the range of $220-250 \mathrm{~m}^{\circ}$. Those changes might originate from both MIP-IV film swelling and shrinking and changes in film electric permittivity incurred by the formation of ferrocenium ions and the simultaneous ingress of counter-ions from the solution to the film and egress of co-ions from the film to the solution.

The injection of $1(40 \mathrm{nM})$ to sample solution caused a significant decrease in the recorded currents. However, SPR signal changes were still visible, but they were twice lower than those in the 1 absence. This result well agrees with those of piezoelectric microgravimetry at EQCM measurements.

Moreover, CV experiments at different scan rates were performed (Fig. S13a in Supplementary material). The logarithms of anodic and cathodic peak currents linearly increased with the logarithm of the potential scan rate increase. The slope of the resulting plot of 0.5 suggests that semi-infinite diffusion governs the process rate [22]. On the other hand, a unit slope indicates that the rate of finite diffusion controls the electrode processes' rate. This behavior is characteristic of species confined on the electrode surface. The fitted calibration plots (Fig. S13b in Supplementary material) obey the following equations, respectively.

$\log \left(I_{\mathrm{pa}}, \mathrm{nA}\right)=1.41\left( \pm 4.52 \times 10^{-2}\right)+0.66\left( \pm 3.12 \times 10^{-2}\right) \log \left(v, \mathrm{~V} \mathrm{~s}^{-1}\right), R^{2}=$ 0.991 .

$\log \left(I_{\mathrm{pc}}, \mathrm{nA}\right)=2.04\left( \pm 6.84 \times 10^{-2}\right)+1.01\left( \pm 4.72 \times 10^{-2}\right) \log \left(v, \mathrm{~V} \mathrm{~s}^{-1}\right), R^{2}=$ 0.991 .

In these equations, $I_{\mathrm{pa}}$ and $I_{\mathrm{pc}}$ are the CV anodic and cathodic peak current, respectively, and $v$ is the potential scan rate.

The above result agrees well with the piezoelectric microgravimetry results (Fig. 4a and $4 \mathrm{~b}$ ). That is, during ferrocene oxidation, the perchlorate ion ingresses the film. However, the film mass increase is too low to compensate for the ferrocene moiety's positive charge generated. Apparently, cations must also diffuse from the film to the solution to account for that. Consequently, a mixed mechanism governs the diffusion making the resulting slope of 0.66 . However, during the backward scan, mostly perchloride ions are expelled from the thin MIP-IV film. Thus, we observe finite diffusion manifested by the slope of 1.01 .

\subsection{Electrochemical determining p-synephrine using self-reporting MIP film-coated electrodes}

Finally, electrodes coated with the MIP-IV film were applied for the determination of $\mathbf{1}$. For that purpose, DPV experiments were performed using a (TBA) $\mathrm{ClO}_{4}$ supporting electrolyte in acetonitrile. The dependence of the self-reporting MIP-IV film electrode response on the $\mathbf{1}$ concentration in solution was quite well described by the LangmuirFreundlich isotherm (Eq. 2) in the concentration range of 2.0-75 nM (Fig. 5b).

$\Delta I=\Delta I_{\max } \frac{K c^{n}}{\left(1+K c^{n}\right)}$

In this equation, $\Delta I, \Delta I_{\max }, K, c$, and $n$ stands for the DPV peak current, maximal DPV peak current, the stability constant of the MIP imprinted molecular cavity complex with the molecule of $\mathbf{1}$, the analyte 1 concentration, and the homogeneity factor, respectively. The isotherm parameters determined for $\mathbf{1}$ and interfering compounds are listed in Table S4 in Supplementary material. The apparent imprinting factor was $\mathrm{IF}=1.9$, and selectivity factors for penicillin G, glucose, tyramine, and urea were equal to $2.9,3.3,3.8$, and 11.8 , respectively.

From a practical analytical point of view, however, it is more convenient to use linear fitting rather than isotherm fitting. That is because the linear fitting enables easy comparing of analytical parameters of different sensors. Therefore, we have constructed calibration plots for the pseudo-linear initial parts of the isotherms (Fig. 5c). The linear dynamic concentration range extended from 0.2 to $8.8 \mathrm{nM}$. The MIP-IV film-coated electrode response obeyed the equation of $\left(I_{\mathrm{DPV}, 0^{-}}\right.$ $\left.I_{\mathrm{DPV}, \mathrm{s}}\right) / I_{\mathrm{DPV}, 0}=0.13\left( \pm 7.59 \times 10^{-3}\right)+3.99 \times 10^{-2}\left( \pm 2.19 \times 10^{-3}\right) c_{p-}$ synephrine, nM, with the correlation coefficient, $R^{2}=0.9822$. The limit of 1 detection was LOD $=0.57 \mathrm{nM}$ at $S / N=3$. The apparent imprinting factor was IF $=2.16$. Moreover, selectivity factors concerning glucose, penicillin G, urea, and tyramine were equal to $2.16,2.22$, 3.34, and 4.06, respectively. These results well agreed with those obtained for isotherm fitting. Significantly, the sensitivity and LOD determined for the selfreporting MIP-IV film-coated electrode were superior to those previously reported for the MIP-(p-synephrine) film without any internal redox probe [15]. That is, chemosensors' sensitivity was 125 times higher, with the imprinting factor and selectivity being only slightly lower than those for previously reported sensing platforms. Moreover, for a higher 1 concentration range, namely $2.0-75 \mathrm{nM}$, semilogarithmic calibration curves were constructed (Fig. S14 in Supplementary material). For these curves, the MIP-IV film-coated electrode response was described by the semilogarithmic calibration curve of $\left(I_{\mathrm{DPV}, 0^{-}} I_{\mathrm{DPV}}\right.$, $\left.{ }_{\mathrm{s}}\right) / I_{\mathrm{DPV}, 0}=0.17\left( \pm 3.23 \times 10^{-2}\right)+0.32\left( \pm 2.87 \times 10^{-2}\right) \log \left(c_{p \text {-synephrine, }}\right.$, 
Table 1

Determination of $\mathbf{1}$ in tablets of the SYNEPHRINE EXTREME dietary supplement.

\begin{tabular}{lllll}
\hline No. & $\begin{array}{l}\text { Known 1 } \\
\text { concentration, } \\
\text { nM }\end{array}$ & $\begin{array}{l}\text { Relative DPV } \\
\text { peak current } \\
\text { change }( \pm \text { st. } \\
\text { dev. })^{\mathrm{a}}\end{array}$ & $\begin{array}{l}\text { Determined 1 } \\
\text { concentration }( \pm \text { st. } \\
\text { dev. }), \mathrm{nM}\end{array}$ & $\begin{array}{l}\text { Recovery } \\
( \pm \text { st.dev. }), \\
\%\end{array}$ \\
\hline 1 & 0.66 & $0.159( \pm 0.015)$ & $0.67( \pm 0.36)$ & $\mathbf{1 0 2}( \pm 55)$ \\
2 & 1.64 & $0.206( \pm 0.016)$ & $1.84( \pm 0.41)$ & $\mathbf{1 1 2}( \pm 25)$ \\
3 & 3.54 & $0.260( \pm 0.019)$ & $3.20( \pm 0.48)$ & $\mathbf{9 0}( \pm 14)$ \\
4 & 4.48 & $0.316( \pm 0.016)$ & $4.60( \pm 0.41)$ & $\mathbf{1 0 3}$ \\
& & $0.386( \pm 0.004)$ & $6.36( \pm 0.11)$ & $\mathbf{9 1}( \pm 1.53)$ \\
5 & 6.96 & $0.440( \pm 0.016)$ & $7.70( \pm 0.40)$ & $\mathbf{8 8}( \pm 4.61)$ \\
6 & 8.76 & $0.492( \pm 0.022)$ & $9.02( \pm 0.54)$ & $\mathbf{8 9}( \pm 5.37)$ \\
\hline
\end{tabular}

${ }^{\text {a }}$ All experiments were repeated three times.

$\mathrm{nM}$ ) with the correlation coefficient, $R^{2}=0.9679$. The limit of 1 detection was LOD $=0.27 \mathrm{nM}$ at $S / N=3$. The apparent imprinting factor was $I F=1.48$. Moreover, selectivity factors for penicillin $G$, glucose, tyramine, and urea were equal to $1.7,1.68,3.25$, and 4.51 , respectively.

Furthermore, the durability of the MIP-IV electrode was examined (Fig. S15 in Supplementary material). Almost no changes in the electrode sensitivity concerning 1 concentration changes were observed within one month. Even after three months of shelf storage, an MIP-IV film-coated electrode revealed sensitivity equal to $\sim 90 \%$ of the original one. Therefore, after additional calibration, it can still be applied for $\mathbf{1}$ determination. Furthermore, the reproducibility of the electrode fabrication process was evaluated (Fig. S16 in Supplementary material). The standard deviation of responses to $4.48 \mathrm{nM}$ of $\mathbf{1}$ for three independent electrodes was equal to $5.45 \%$.

\subsection{Electrochemical determining p-synephrine using self-reporting MIP film-coated electrodes in real samples of dietary supplements}

To highlight the applicability of the MIP-film coated electrodes for $p$ synephrine determinations in real samples, $\mathbf{1}$ was determined in the SYNEPHRINE EXTREME dietary supplement. For that purpose, 1-containing tablets of the supplement were ground and extracted (Section S10 in Supplementary material). Then this sample was used for $\mathbf{1}$ determination with MIP-IV film-coated electrode in the $\mathbf{1}$ concentration ranging from 0.6 to $10 \mathrm{nM}$. Calculated recoveries values using a linear calibration plot (Fig. 5c, curve 1') are at an acceptable level (Table 1).

\section{Conclusions}

Herein, a redox self-reporting MIP film was first deposited on an electrode and then applied for fabricating selective electrochemical chemosensors to determine the target analyte, $\mathbf{1}$, in the redox probe free test solutions. A bis-(2,2'-bithienyl)-4-ferrocenylphenyl methane 3 was specially designed, synthesized, and then applied for MIP film deposition to immobilize covalently a ferrocene redox probe in the polymer matrix. The MIP film electropolymerization conditions were carefully optimized (Table S5 in Supplementary material). In the MIP-IV film deposited under these conditions, even $40 \%$ of the ferrocene moieties participated in the chemosensor's response. For that purpose, it was necessary to copolymerize the sulfonyl acid moiety containing monomer, 4, in the MIP matrix. The deposited polymer film's thickness and morphology appeared to be crucial parameters for the MIP-IV filmbased chemosensor performance. Moreover, the MIP-IV film-based chemosensor's analytical parameters were superior to those for similar previously reported chemosensors lacking a self-reporting mechanism. The applicability of the MIP-film coated electrodes was proven by $\mathbf{1}$ determination in dietary supplement samples.

\section{Declaration of Competing Interest}

The authors report no declarations of interest.

\section{Acknowledgments}

The authors acknowledge Dr. Marta Sosnowska for discussion and Dr. Pawel Borowicz for recording PM-IRRAS spectra. The National Science Centre of Poland $(\mathrm{NCN})$ funded the research described herein through MINIATURA grant No. 2017/01/X/ST4/00471 to M.C. and OPUS grant No. $2018 / 29 / \mathrm{B} / \mathrm{ST} 5 / 02335$ to P.S.S.

\section{Appendix A. Supplementary data}

Supplementary material related to this article can be found, in the online version, at doi:https://doi.org/10.1016/j.snb.2021.130276.

\section{References}

[1] M. Cieplak, W. Kutner, Artificial biosensors: how can molecular imprinting mimic biorecognition? Trends Biotechnol. 34 (2016) 922-941.

[2] P.S. Sharma, Z. Iskierko, A. Pietrzyk-Le, F. D’Souza, W. Kutner, Bioinspired intelligent molecularly imprinted polymers for chemosensing: a mini review, Electrochem. Commun. 50 (2015) 81-87.

[3] L. Chen, X. Wang, W. Lu, X. Wu, J. Li, Molecular imprinting: perspectives and applications, Chem. Soc. Rev. 45 (2016) 2137-2211.

[4] L. Uzun, A.P.F. Turner, Molecularly-imprinted polymer sensors: realising their potential, Biosens. Bioelectron. 76 (2016) 131-144.

[5] P. Rebelo, E. Costa-Rama, I. Seguro, J.G. Pacheco, H.P.A. Nouws, M. Cordeiro, et al., Molecularly imprinted polymer-based electrochemical sensors for environmental analysis, Biosens. Bioelectron. 172 (2021), 112719.

[6] J. Ashley, M.-A. Shahbazi, K. Kant, V.A. Chidambara, A. Wolff, D.D. Bang, et al., Molecularly imprinted polymers for sample preparation and biosensing in food analysis: progress and perspectives, Biosens. Bioelectron. 91 (2017) 606-615.

[7] M. Feroz, P. Vadgama, Molecular imprinted polymer modified electrochemical sensors for small drug analysis: progress to practical application, Electroanalysis 32 (2020) 2361-2386.

[8] T.-P. Huynh, P.S. Sharma, M. Sosnowska, F. D'Souza, W. Kutner, Functionalized polythiophenes: recognition materials for chemosensors and biosensors of superior sensitivity, selectivity, and detectability, Prog. Polym. Sci. 47 (2015) 1-25.

[9] Y. Yoshimi, A. Narimatsu, K. Nakayama, S. Sekine, K. Hattori, K. Sakai, Development of an enzyme-free glucose sensor using the gate effect of a molecularly imprinted polymer, J. Artif. Organs 12 (2009) 264-270.

[10] Y. Yoshimi, K. Sato, M. Ohshima, E. Piletska, Application of the' gate effect' of a molecularly imprinted polymer grafted on an electrode for the real-time sensing of heparin in blood, Analyst 138 (2013) 5121-5128.

[11] P.S. Sharma, A. Garcia-Cruz, M. Cieplak, K.R. Noworyta, W. Kutner, 'Gate effect' in molecularly imprinted polymers: the current state of understanding, Curr Opin Electroche 16 (2019) 50-56.

[12] F.T.C. Moreira, S. Sharma, R.A.F. Dutra, J.P.C. Noronha, A.E.G. Cass, M.G.F. Sales, Protein-responsive polymers for point-of-care detection of cardiac biomarker, Sens. Actuators B Chem. 196 (2014) 123-132.

[13] F.T.C. Moreira, R.A.F. Dutra, J.P.C. Noronha, J.C.S. Fernandes, M.G.F. Sales, Novel biosensing device for point-of-care applications with plastic antibodies grown on Au-screen printed electrodes, Sens. Actuators B Chem. 182 (2013) 733-740.

[14] P. Jolly, V. Tamboli, R.L. Harniman, P. Estrela, C.J. Allender, J.L. Bowen, AptamerMIP hybrid receptor for highly sensitive electrochemical detection of prostate specific antigen, Biosen Bioelectron 75 (2016) 188-195.

[15] P. Lach, M. Cieplak, M. Majewska, K.R. Noworyta, P.S. Sharma, W. Kutner, Gate Effect" in p-Synephrine Electrochemical Sensing with a Molecularly Imprinted Polymer and Redox Probes, Anal. Chem. 91 (2019) 7546-7553.

[16] J.R. Arch, beta(3)-Adrenoceptor agonists: potential, pitfalls and progress, Eur. J. Pharmacol. 440 (2002) 99-107.

[17] L.G. Rossato, V.M. Costa, R.P. Limberger, d.B.M. L, F. Remiao, Synephrine: from trace concentrations to massive consumption in weight-loss, Food Chem. Toxicol. 49 (2011) 8-16.

[18] D. Udomsap, C. Branger, G. Culioli, P. Dollet, H. Brisset, A versatile electrochemical sensing receptor based on a molecularly imprinted polymer, Chem. Commun. 50 (2014) 7488-7491.

[19] E. Mazzotta, A. Turco, I. Chianella, A. Guerreiro, S.A. Piletsky, C. Malitesta, Solidphase synthesis of electroactive nanoparticles of molecularly imprinted polymers. A novel platform for indirect electrochemical sensing applications, Sens Actuatators B 229 (2016) 174-180.

[20] H. Tang, J.R. Chen, Y.B. Zeng, Z.Y. Li, H. Huang, L. Li, An electrochemical sensor for 1-naphthylamine based on a novel composite of cyclodextrin-graphene and molecularly imprinted poly(vinylferrocene), Anal. Methods 8 (2016) 1681-1689.

[21] S. Rebocho, C.M. Cordas, R. Viveiros, T. Casimiro, Development of a ferrocenylbased MIP in supercritical carbon dioxide: Towards an electrochemical sensor for bisphenol A, J. Supercrit. Fluids 135 (2018) 98-104. 
[22] A.J. Bard, L.R. Faulkner, Electrochemical Methods: Fundamentals and Applications, 2nd ed., NJ: John Wiley \& Sons, Hoboken, 2001.

[23] C. Criado, P. Galan-Montenegro, P. Velasquez, J.R. Ramos-Barrado, Diffusion with general boundary conditions in electrochemical systems, J. Electroanal. Chem. 488 (2000) 59-63.

[24] J. Bisquert, G. Garcia-Belmonte, F. Fabregat-Santiago, P.R. Bueno, Theoretical models for ac impedance of finite diffusion layers exhibiting low frequency dispersion, J. Electroanal. Chem. 475 (1999) 152-163.

[25] J. Huang, Diffusion impedance of electroactive materials, electrolytic solutions and porous electrodes: warburg impedance and beyond, Electrochim. Acta 281 (2018) $170-188$.

[26] J. Bisquert, Theory of the impedance of electron diffusion and recombination in a thin layer, J. Phys. Chem. B 106 (2002) 325-333.

[27] G. Valincius, M. Mickevicius, T. Penkauskas, M. Jankunec, Electrochemical impedance spectroscopy of tethered bilayer membranes: an effect of heterogeneous distribution of defects in membranes, Electrochim. Acta 222 (2016) 904-913.

[28] G. Sauerbrey, Verwendung von schwingquarzen zur wagung dunner schichten und zur mikrowagung, Z Phys 155 (1959) 206-222.

Patrycja Lach received the M.Sc. degree in chemistry from the Jagiellonian University and B.Eng. Degree in materials science from the AGH University of Science and Technology. Currently, she is a Ph.D. candidate at the Institute of Physical Chemistry of the Polish Academy of Sciences. Her research is mainly concerned with development of electrochemical sensors based on molecularly imprinted polymers for food toxin determination. Her supervisor is Prof. Wlodzimierz Kutner, and her subsidiary supervisor is Dr. Maciej Cieplak.

Maciej Cieplak received his Ph.D. in 2013 from the Institute of Organic Chemistry PAS, Warsaw, Poland under supervision of Prof. S. Jarosz. He did one year his PostDoc in the Institute of Physical Chemistry PAS, under prof. W. Kutner supervision. Since then, he has been continuing his research activity in the IPC PAS in field of application of MIPs in selective sensors devising.

Krzysztof R. Noworyta was born September 12, 1970. He completed his chemistry studies at the Warsaw University of Technology. He then started Ph.D. studies in the Institute of Physical Chemistry Polish Academy of Sciences under the supervision of Prof. Wlodzimierz Kutner. He was working on the electrosynthesis of fullerene derivatives. After finishing Ph.D. studies in 2001, he joined the group of Prof. Jan Augstynski at the Mineral, Analytical and Applied Chemistry Department of the Geneva University. He worked on the development of carbon-doped $\mathrm{TiO}_{2}$ photocatalysts for water splitting. In 2006 he returned to the Institute of Physical Chemistry PAS, where he is working until now. His research interests include the development of sensors based on molecularly imprinted polymers, studies of supramolecular interactions in thin films of the thiophene, fullerene and porphyrin derivatives, and development and studies of inorganic materials for photoelectrochemical applications.

Piotr Pięta received his PhD degree in 2009 from the Institute of Physical Chemistry PAS under supervision of Prof. W. Kutner. He has experience in the electrochemical research of energy storage polymers and catalysts. He also specializes in model biological membranes in terms of the mechanisms of interactions with biologically active molecules. $\mathrm{He}$ is an expert in electrochemical quartz crystal microbalance measurements, high-resolution imaging using electrochemical atomic force, and scanning tunneling microscopy. He is a co-author of original articles in high-impact journals (31), book chapter (1), and patents (4).
Wojciech Lisowski Qualifications: M.Sc., 1972, University of Warsaw, Warsaw, Poland. PhD, 1980, Institute of Physical Chemistry, PAS, Warsaw, Poland. D.Sc., 1996, Institute of Physical Chemistry, PAS, Warsaw, Poland. Experience: Surface and interface studies of solid state materials. Familiar with UHV techniques and the measurements: XPS, AES, SAM, STM, TEM, TPD, MS, ellipsometry, work function, sticking probability

Jakub Kalecki received B.Sc. in Chemistry and M.Sc. in Advanced Instrumental Analysis at the University of Warsaw, Poland. During this period, he developed nanostructured catalytic materials for oxygen and $\mathrm{CO}_{2}$ reduction reaction. Now he is doing research towards his Ph.D. degree under supervision of prof. P.S. Sharma in the Institute of Physical Chemistry PAS, Warsaw, Poland. His research is mainly focused on development of electrochemical sensors based on macroporous molecularly imprinted polymers.

Raghu Chitta received his Bachelor's degree from Kakatiya University and M.Sc. in General Chemistry from University of Hyderabad, India. He pursued his Ph.D. in Supramolecular and Analytical Chemistry at Wichita State University, Wichita, Kansas, USA, under the supervision of Prof. Francis D'Souza (now at University of North Texas, Denton). He then moved to University of Minnesota, Twin Cities followed by University of Houston to pursue his post-doctoral studies. After working at Central University of Rajasthan, he moved to National Institute of Technology Warangal and working as an Assistant Professor in the Department of Chemistry.

Francis D'Souza is a Regents Professor of Chemistry and Materials Science and Engineering at the University of North Texas, Denton, TX. He received Ph.D. from the Indian Institute of Science, Bangalore, India and post-doctoral studies at the University of Houston and University of Dijon, France. His research covers wide areas of chemistry, nanophotonics and materials science. Principal research interests include supra and nanomolecular chemistry of photosensitizer-carbon nanomaterials, advanced functional materials for light energy harvesting and photovoltaics, sensors and biosensors, and ultrafast spectroscopy.

Wlodzimierz Kutner received his M.Sc. (1971) and Ph.D. (1975) in Chemistry Degrees from Warsaw University, Warsaw, Poland, and his D.Sc. (habilitation) in Chemistry Degree (1995) from the Institute of Physical Chemistry, Polish Academy of Sciences (IPC PAS), Warsaw, Poland. He performed his research at the U.S. state universities of Cincinnati OH (1976-1977, postdoc to Prof. H. Mark, Jr.), Chapel Hill NC (1983-1985, research fellow to Prof. R. Murray), Houston TX (1991-1993, research professor to Prof. K. Kadish), Wichita KS (1994-2011, visiting scholar to Prof. F. D'Souza, eight short visits). Now, he is a Full Professor at IPC PAS and the Department of Mathematics and Natural Sciences. School of Science of the Cardinal Stefan Wyszynski University, Warsaw, Poland. In 1998-2007 he was a Titular Member of Analytical Chemistry Division and Interdivisional Committee of Terminology, Nomenclature, and Symbols of IUPAC. His research interests involve the supramolecular chemistry of inclusion and molecularly imprinted polymers, electrochemistry and spectroscopy of interfaces, and Langmuir and Langmuir-Blodgett films of fullerenes, carbon nanotubes, and metalloporphyrins for devices of energy conversion and storage, and electrodes modified with functionalized conducting polymers for chemical sensors and biosensors. 180 publications, Hirsch Index 40 (Web of Science).

Piyush Sindhu Sharma is currently an Associate Professor and Group Leader of the Functional Polymers Team at the Institute of Physical Chemistry of the Polish Academy of Sciences (IPC PAS), Warsaw, Poland. His research interest includes Supramolecular chemistry, conducting polymers, stimuli-responsive polymers, and chemosensing. Prof. Sharma has authored over 60 publications and edited a book. Moreover, he served as a Guest Editor for MDPI and Elsevier journals. 